\title{
Viscoelastic Properties of Poly(vinyl methyl ether)
}

\author{
Yoshiaki Takahashi, Hirokazu Suzuki, Yoshiki Nakagawa, \\ Masayoshi YamaguCHI, and Ichiro Noda \\ Department of Synthetic Chemistry, Nagoya University, \\ Chikusa-ku, Nagoya 464-01, Japan
}

(Received January 14, 1991)

\begin{abstract}
Viscoelastic properties of fractionated poly(vinyl methyl ether) in melts were measured in oscillation flow in the molecular weight range of $2.44 \times 10^{4}-13.4 \times 10^{4}$. It was found that the molecular weight dependences of zero-shear viscosity $\eta^{\circ}$ and steady-state compliance $J_{\mathrm{c}}$ are qualitatively the same as those of other linear polymers, and the $J_{\mathrm{e}}$ value in entangled region is about $3 \times 10^{-6}\left(\mathrm{~cm}^{2} \mathrm{dyn}^{-1}\right)$, while the plateau modulus $G_{\mathrm{N}}^{0}$ is about $2.6 \times 10^{6}\left(\mathrm{dyn} \mathrm{cm}^{-2}\right)$.

KEY WORDS Poly(vinyl methyl ether) / Plateau Modulus / Zero-Shear

Viscosity / Steady-State Compliance / Critical Molecular Weight /
\end{abstract}

Poly(vinyl methyl ether) (PVME), which is one of the important polymers, is widely used for producing adhesives, coatings, plasticizers, etc. in industries. Moreover, it is also used for studying phase separation ${ }^{1-3}$ and viscoelastic properties of polymer blends ${ }^{4-8}$ in science since polystyrene(PS)-PVME blends are soluble below certain temperatures or have LCST in the phase diagram. Recently, the effects of shear flow on phase separation of polymer blends are also studied by measuring small angle neutron scattering and viscosity of PS-PVME blends in steady-shear flow. ${ }^{9}$ For discussing these experimental data of PSPVME blends in steady-shear flow, it is important to know the viscoelastic properties of each component of the blends.

The viscoelastic properties of PS have been well studied, ${ }^{10-12}$ but only a few viscoelastic data of PVME have been published. Takatori et $a .^{6}$ reported that the molecular weight between entanglements $M_{\mathrm{e}}$ evaluated from the plateau modulus $G_{\mathrm{N}}^{0}$ of PS-PVME blend, in which PS molecules are not entangled, is about $8.5 \times 10^{3}$. While Brekner et al.$^{4}$ reported that $M_{\mathrm{e}} \simeq 1.5 \times 10^{4}$ for PVME with a broad molecular weight distribution. The main reasons why the viscoelastic properties of PVME have not been well studied are as follows: 1) PVME is readily degraded by oxidation. ${ }^{13}$ 2) It readily absorbs moisture. 3 ) It is difficult to get the samples having narrow molecular weight distribution over a wide range of molecular weights.

In this work, therefore, we study the molecular weight and temperature dependences of viscoelastic properties, and the critical molecular weight of entanglement for well-fractionated PVME samples with various molecular weights in melts taking care of the degradation and the absorption of moisture.

\section{EXPERIMENTAL}

\section{Fractionation}

PVME sample was purchased from Polysciences Inc. as a $50 \%$ aqueous solution. The solution was mixed with toluene to extract PVME and the toluene solution was dried by calcium chloride. After that, the toluene solution was added to a large amount of $n$-hexane to precipitate PVME. The sample 
thus obtained were successingly fractionated few times in a mixture of benzene $/ n$-hexane with the mixing ratio of about $1: 4$, by varying the temperature. The final fractions were dissolved in benzene to be freeze-dried and kept in a decicator in vacuo.

\section{Characterization}

The number average molecular weights $M_{n}$ of four fractions (F5-1, F6-2, F6-3 and F6-4-4) were measured by osmometry in toluene at $30^{\circ} \mathrm{C}$ using a Hewlett Packard High Speed Membrane Osmometer Type 502. The weight average molecular weight $M_{w}$ of a high molecular weight sample, kindly supplied by National Institute of Standards and Technology, was measured by light scattering in 2-butanone at $25^{\circ} \mathrm{C}$ with a Fica 50 Automatic Light Scattering Photometer. The wave length used was $436 \mathrm{~nm}$ and the refractive index increment was $0.0944 \mathrm{~cm}^{3} \mathrm{~g}^{-1} \cdot{ }^{14}$ This sample $\left(M_{w}=4.95 \times 19^{5}\right)$ was only used to make the calibration curve for gel permeation chromatography (GPC) mentioned below.

Elution volume of GPC were measured by Tosoh High Speed Chromatograph HLC-802A with GMHXL $\times 2$ mixed column. The eluting solvent used was tetrahydrofuran and the flow rate was $1 \mathrm{~cm}^{3} \mathrm{~min}^{-1}$. A calibration curve for PVME was made by trial and error to reproduce the number and weight average molecular weights of samples measured by osmometry and light scattering. The $M_{n}, M_{w}$ and $M_{w} / M_{n}$ values of all the samples tabulated in Table I were evaluated by using the calibration curve. A fraction $F 1^{\prime}$ has a relatively broad molecular weight distribution as it was not well fractionated to need a large amount of the sample for determining the temperature shift factor $a_{\mathrm{T}}$.

\section{Viscoelastic Measurements}

Viscoelastic properties were measured by a Mechanical Spectrometer type RMS800 of Rheometrics Inc. in oscillation flow. A disk and plate geometry with a diameter of $2.5 \mathrm{~cm}$
Table I. Molecular characteristics of PVME determined by GPC

\begin{tabular}{lccc}
\hline Sample code & $M_{n} \times 10^{-4}$ & $M_{w} \times 10^{-4}$ & $M_{w} / M_{n}$ \\
\hline F4-2 & 8.42 & 13.4 & 1.43 \\
F5-2 & 7.79 & 11.1 & 1.28 \\
F5-1 & 5.83 & 9.90 & 1.40 \\
F6-1 & 4.50 & 6.86 & 1.37 \\
F6-2 & 3.22 & 4.82 & 1.35 \\
F6-3 & 2.77 & 4.36 & 1.41 \\
F6-4-2 & 2.90 & 3.98 & 1.24 \\
F6-4-4 & 1.72 & 2.44 & 1.73 \\
F1' & 2.60 & 5.69 & 1.97 \\
\hline
\end{tabular}

was used for all the measurements. Dry nitrogene gas was used in the temperature control system of RMS800 to prevent the oxidation of PVME and also the absorption of moisture. The shift factor $a_{\mathrm{T}}$ for PVME was determined by using $\mathrm{Fl}^{\prime}$ in the temperature range from $30^{\circ} \mathrm{C}$ to $130^{\circ} \mathrm{C}$. In the measurement of temperature dependence, a fresh sample was used at each temperature in the high temperature range to avoid the degradation and the absorption of moisture.

Measurements for all the other samples were carried out at $80.6^{\circ} \mathrm{C}$ to study the viscoelastic properties at the terminal region. Viscoelastic properties of the sample F5-1 was also measured at $30^{\circ} \mathrm{C}$ to cover the wide range of frequency. After each measurement, the molecular weight distribution of the sample was measured by GPC to examine the degradation.

\section{RESULTS AND DISCUSSION}

\section{Temperature Dependence}

Figures 1 and 2 show the master curves of storage modulus $G^{\prime}$ and loss modulus $G^{\prime \prime}$ for the samples $F 1^{\prime}$ in the temperature range from $30^{\circ} \mathrm{C}$ to $130^{\circ} \mathrm{C}$, and for $\mathrm{F} 5-1$ at $30^{\circ} \mathrm{C}$ and $80.6^{\circ} \mathrm{C}$, respectively. In these figures, the reference temperature $T_{\mathrm{r}}$ is $80.6^{\circ} \mathrm{C}$, and $G^{\prime}$ and $G^{\prime \prime}$ are shown by the solid and broken lines, respectively. It is well known that the shift factor $a_{\mathrm{T}}$ is independent of molecular weight 


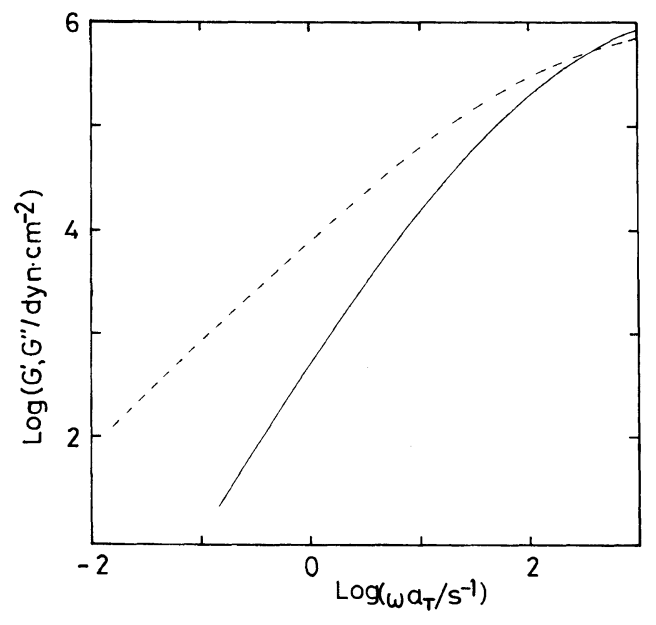

Figure 1. Master curves of $G^{\prime}$ (solid line) and $G^{\prime \prime}$ (broken line) for sample $F 1^{\prime}$. The reference temperature is $80.6^{\circ} \mathrm{C}$.

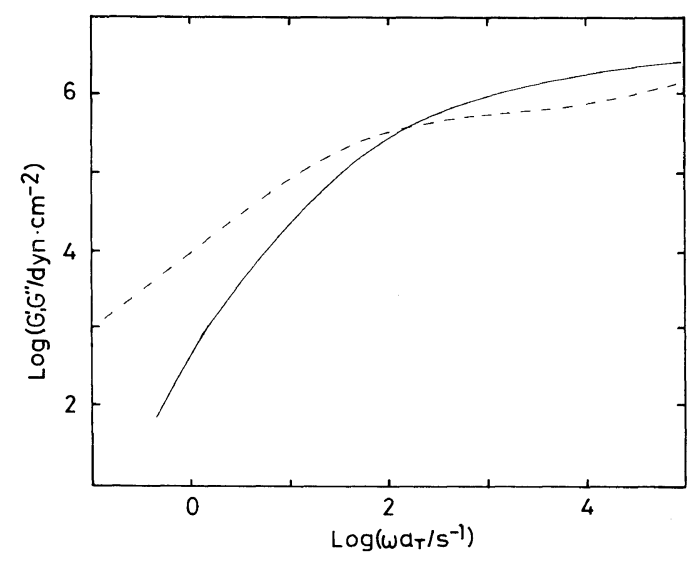

Figure 2. Master curves of $G^{\prime}$ (solid line) and $G^{\prime \prime}$ (broken line) for sample F5-1. The reference temperature is $80.6^{\circ} \mathrm{C}$.

and molecular weight distribution, if the molecular weight of sample is high enough. ${ }^{12,13}$ This is also the case for PVME since the $a_{\mathrm{T}}$ values used at $30^{\circ} \mathrm{C}$ in Figures 1 and 2 are the same. Therefore, we use the $a_{\mathrm{T}}$ values in Figure 1 for PVME in melts.

Figure 3 shows plots of $\log a_{\mathrm{T}} \cdot v s . T^{-1}\left(\mathrm{~K}^{-1}\right)$. The data are connected smoothly by the solid line, which follows the WLF equation (eq 1).

$$
\log a_{\mathrm{T}}=\frac{-C_{1}\left(T-T_{\mathrm{r}}\right)}{C_{2}+\left(T-T_{\mathrm{r}}\right)}
$$

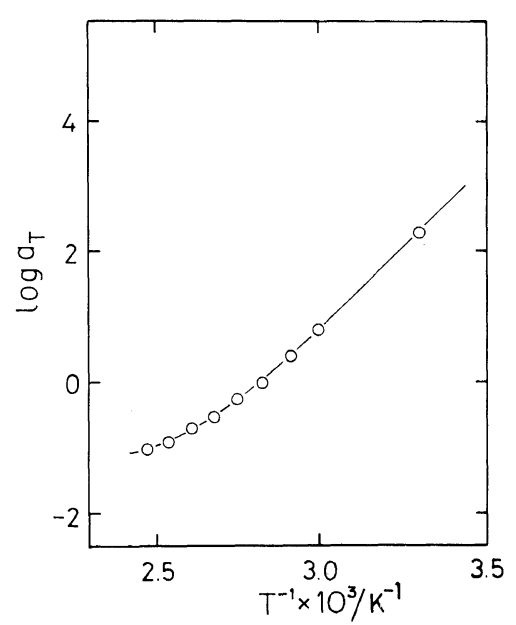

Figure 3. Plots of $\log a_{\mathrm{T}} v s . T^{-1}\left(\mathrm{~K}^{-1}\right)$ for PVME. The solid line shows the WLF equation.

where $C_{1}$ and $C_{2}$ are the constants, which are determined to be 4.01 and 136.9 , respectively, from the slope and the intercept of plots of $-\left(T-T_{\mathrm{r}}\right) / \log a_{\mathrm{T}} v s .\left(T-T_{\mathrm{r}}\right)$.

Plateau Modulus, Zero-Shear Viscosity and Steady-State Compliance

In Figure 2, we may regard the high frequency region where $\omega a_{\mathrm{T}}$ is around $10^{4} \mathrm{~s}^{-1}$ as a rubbery plateau region, since the magnitude of $G^{\prime \prime}$ is smaller than that of $G^{\prime},{ }^{12}$ but we cannot determine precisely the plateau modulus $G_{\mathrm{N}}^{0}$ since $G^{\prime}$ increases very slightly but continuously, and the maximum in $G^{\prime \prime}$ does not clearly appear. This may be due to the fact that the PVME sample used has the wider molecular weight distribution than other anionically polymerized samples such as polystyrene (PS), which shows a relatively flat plateau in $G^{\prime}$ and the maximum in $G^{\prime \prime} .^{10}$ Therefore, we assume that the mean value of $G^{\prime}\left(2.58 \times 10^{6}{\left.\mathrm{dyn} \mathrm{cm}^{-2}\right)}^{-2}\right.$ at the high frequency region in Figure 2 is equal to $G_{\mathrm{N}}^{0}$. Then we have $M_{\mathrm{e}} \simeq 1.2 \times 10^{4}$ from $M_{\mathrm{e}}=\rho R T / G_{\mathrm{N}}^{0}$ where $\rho=1.01 \mathrm{~g} \mathrm{~cm}^{-3}$ at $80.6^{\circ} \mathrm{C}^{8}$ The $M_{\mathrm{e}}$ value thus estimated is slightly higher than the value reported by Takatori et $a l .{ }^{6}$ but slightly lower than the value reported by Brekner et al. $^{4}$ Graessley and Edwards ${ }^{15}$ ) 


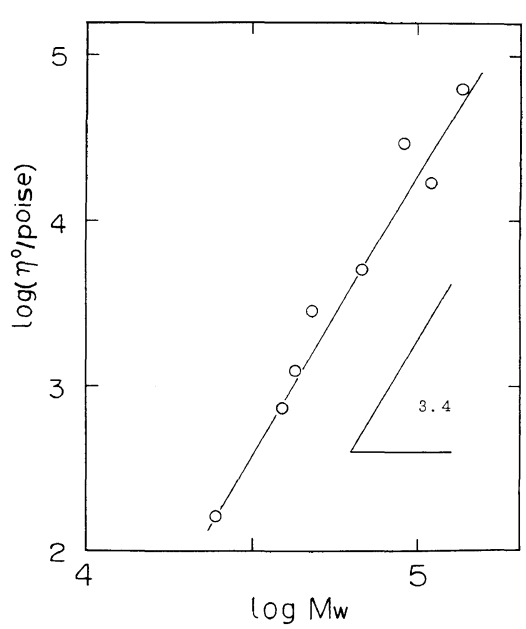

Figure 4. Double logarithmic plots of $\eta^{\circ} v s . M_{w}$ for PVME at $80.6^{\circ} \mathrm{C}$.

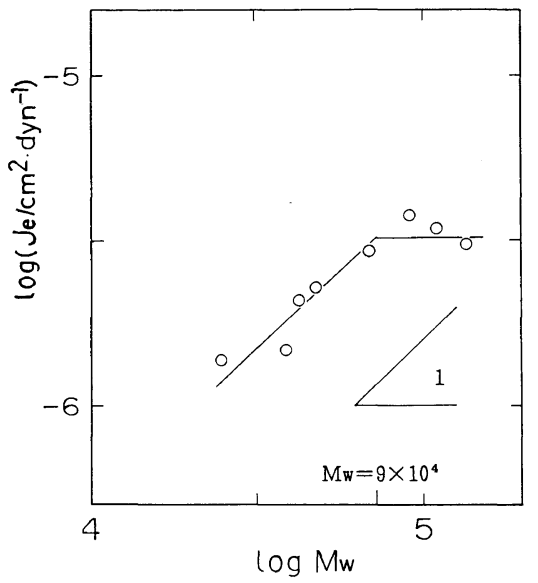

Figure 5. Double logarithmic plots of $J_{\mathrm{e}} v s . M_{w}$ for PVME at $80.6^{\circ} \mathrm{C}$.

presented a universal power law, relating $G_{\mathrm{N}}^{0}$ to the unperturbed dimension and reported that it is valid for $G_{\mathrm{N}}^{0}$ in melts of 15 polymer species so far published. It is to be noted that the $G_{\mathrm{N}}^{0}$ value of PVME assumed in this work also follows the universal power law.

As shown in Figure 2 as an example, we observe the terminal region where $G^{\prime} \propto \omega^{2}$ and $G^{\prime \prime} \propto \omega$, in the low frequency range for all the samples. Therefore, the zero shear viscosity $\eta^{\circ}$ and the steady state compliance $J_{\mathrm{e}}$ can be evaluated by using the following equations.

$$
\begin{gathered}
\eta^{\circ}=\lim _{\omega \rightarrow 0} \frac{G^{\prime \prime}}{\omega} \\
J_{\mathrm{e}}=\lim _{\omega \rightarrow 0} \frac{1}{\eta^{\circ 2}} \frac{G^{\prime}}{\omega^{2}}
\end{gathered}
$$

Figure 4 shows double logarithmic plots of $\eta^{\circ}$ vs. $M_{w}$. It is clear from the figure that all the data can be represented by the 3.4 th power law like other linear polymers, ${ }^{11,12}$ though the data are somewhat scattered. This figure reveals that the critical molecular weight $M_{\mathrm{C}}$ for entanglement effects on $\eta^{\circ}$ is lower than $M_{w}=2.44 \times$ $10^{4}$. If we assume the relationship $M_{\mathrm{C}} \simeq 2 M_{\mathrm{e}}$, which is valid for ordinary linear polymers, ${ }^{11,12,15}$ we have $M_{\mathrm{C}} \simeq 2 \times 10^{4}$ for PVME. This value is consistent with the viscosity data.

Figure 5 shows double logarithmic plots of $J_{\mathrm{e}}$ vs. $M_{w}$. Here, we use $M_{w}$ as usual, though, $J_{\mathrm{e}}$ strongly depends on molecular weight distribution. ${ }^{11,12}$ In the low $M_{w}$ region, $J_{\mathrm{e}}$ is proportional to $M_{w}$, and seems to become independent of $M_{w}$ in the high $M_{w}$ region. The critical molecular weight $M_{\mathrm{C}}^{\prime}$ and the limiting value of $J_{\mathrm{e}}$ are estimated to be about $9 \times 10^{4}$ and $3 \times 10^{-6} \mathrm{~cm}^{-2} \mathrm{dyn}^{-1}$ ) from this figure, respectively. The order of $J_{\mathrm{e}}$ is the same as that for other linear polymers so far studied and the value is slightly higher than that of PS. ${ }^{10-12}$ The product $G_{\mathrm{N}}^{0} J_{\mathrm{e}}$ can be regarded as a measure of the breadth of terminal relaxation time distribution, and its values were reported to be 3 -5 for nearly monodisperse polymers. ${ }^{11,12,15}$ The $G_{\mathrm{N}}^{0} J_{\mathrm{e}}$ value for PVME in this work is about 7.7, reflecting the broad relaxation time distribution as can be seen in Figure 2.

In summary we conclude that the molecular weight dependences of $\eta^{\circ}$ and $J_{\mathrm{e}}$ of fractionated PVME are qualitatively the same as those of other polymers studied well such as PS. The characteristic molecular weights, $G_{\mathrm{N}}^{0}$ and $J_{\mathrm{e}}$ values are in the same order with most of other polymers so far studied. 
Viscoelastic Properties of Poly(vinyl methyl ether)

\section{REFERENCES}

1. T. Nishi, T. T. Wang, and T. K. Kwei, Macromolecules, 8, 227 (1975).

2. C. C. Han, B. J. Bauer, J. C. Clark, Y. Muroga, Y. Matsushita, M. Okada, Q. Tran-Cong, T. Chang, and I. C. Sanchez, Polymer, 29, 2002 (1988).

3. T. Shiomi, F. Hamada, T. Nasako, K. Yoneda, K. Imai, and A. Nakajima, Macromolecules, 23, 229 (1990).

4. M.-J. Brekner, H.-J. Cantow, and H. A. Schneider, Polym. Bull., 14, 17 (1985).

5. J. D. Katsaros, M. F. Malone, and H. H. Winter, Polym. Bull., 16, 83 (1986).

6. E. Takatori, S. Sibasaki, K. Osaki, and M. Kurata, J. Soc. Rheol., Jpn., 16, 171 (1988).

7. A. A. L. Choplin and R. E. Prud'homme, J. Polym.
Sci., B, 26, 2279 (1988).

8. R. Stadler, L. L. Freitas, V. Krieger, and S. Klotz, Polymer, 29, 1643 (1988).

9. A. I. Nakatani, H. Kim, Y. Takahashi, Y. Matsushita, A. Takano, B. J. Bauer, and C. C. Han, J. Chem. Phys., 93, 795 (1990).

10. S. Onogi, T. Masuda, and K. Kitagawa, Macromolecules, 3, 109 (1970).

11. W. W. Graessley, Adv. Polym. Sci., 16, 1 (1974).

12. J. D. Ferry, "Viscoelastic Properties of Polymers," 3rd ed, Wiley, New York, 1980.

13. H. Park, E. M. Pearce, and T. K. Kwei, Macromolecules, 23, 434 (1990).

14. J. A. Manson and G. J. Arquette, Macromol. Chem., 37, 187 (1990).

15. W. W. Graessley and S. F. Edwards, Polymer, 22, 1329 (1981). 